\title{
Transport of aerosols in the Mediterranean coastal zone
}

\author{
J. Piazzola, A. Demoisson \& G. Tedeschi \\ Mediterranean Institute of Oceanography (MIO UM $n^{\circ} 110$ ), \\ Southern University of Toulon-Var, France
}

\begin{abstract}
Aerosol particles in coastal areas result from a complex mixing between seaspray aerosols locally generated at the sea surface by breaking waves and a continental component arising from natural and/or anthropogenic sources. We present a study on the aerosol transport in a French Mediterranean coastal zone based on physico-chemical characterization of the particle size distributions measured on the island of Porquerolles. The results are analyzed using a $2 \mathrm{D}$ model, the MACMod model, dedicated to the aerosol transport at a local scale. A part of the analysis deals with the dispersion of organic compounds in the Marine Boundary Layer (MABL). This shows that, even at very short fetch, the seaspray particles represent a strong contribution of the aerosol size distributions measured in the coastal zone. In contrast, the low wind speed conditions correspond to air masses that are strongly impacted by pollution transported over the Mediterranean. Under higher wind speed conditions, aerosol number and mass concentrations of smaller sizes are lowered due to the dispersion of anthropogenic pollutants. However, the model simulations show that the lifetime of these submicronic particles in the atmosphere, which are characteristics of the anthropogenic influence in coastal areas, is rather large.
\end{abstract}

Keywords: coastal aerosols, anthropogenic compounds.

\section{Introduction}

The role of atmospheric aerosols in climate change remains an important scientific challenge. This is mainly due to the heterogeneous spatial and temporal distribution of tropospheric aerosol particles, their different origins (natural or anthropogenic), and their physical and chemical transformation in the free 
troposphere. In marine areas, the sea-sprays generated at the air-sea interface by wave breaking represent a major component of the natural aerosol mass (Andreae [1]; Yoon et al. [2]; Piazzola et al. [3]) and therefore are important in the Earth radiative budget (e.g., Mulcahy et al. [4]). In addition, they have a significant influence on the coastal urban air quality (Knipping and Dabdub [5]) through their ability to have chemical and physical interactions with other aerosol species and gases and then sea-spray aerosols transport a large variety of organic matter (Paerl et al. [6]). Sea-spray is made primarily of sodium chloride $(\mathrm{NaCl})$ and small amounts of sulphate, calcium and potassium, but they can also contain significant amounts of organic carbon. The organic component was mainly attributed to bubble bursting processes, due to the predominantly insoluble and surface active character of organic carbon in the marine aerosols (Ceburnis et al. [7]).

Over the Mediterranean basin, the atmospheric aerosol represents a mixing between particles produced by natural processes (of both continental and marine origin) and particles of anthropogenic origin released in dense urban areas. As a consequence, the sea-spray aerosol is often strongly impacted by anthropogenic emissions. In the Mediterranean Sea, the amount of aqueous phase pollutants are expected to be much higher than in the Atlantic due to important inputs from major continental rivers such as the Rhône (France) or Pô (Italy). Pollution in coastal waters combined with the high intensity of solar radiation in the Mediterranean area can cause an excess in nutrients, as phosphate and nitrate compounds resulting in eutrophication processes throughout the year (Jamet et al. [8]). During laboratory measurements, surfactants present in artificial sea water also proved to modify the aerosol size distribution (Sellegri et al. [9]).

The main objective of the present paper is to determine the extent to which marine aerosol is impacted by anthropogenic activities by studying the mixing between sea-sprays produced for short fetch conditions and continental sources. The study area is located on the French Mediterranean coast, which represents a densely populated zone where large amounts of aerosol particles of anthropogenic origin are expected. We present an analysis of aerosols measured in the Mediterranean coast in May 2007 on the island of Porquerolles, which is located at about $5 \mathrm{~km}$ from the coastline. The present study focuses on offshore winds to investigate the anthropogenic impact of polluted aerosols transported from the urban coastal area on the marine atmosphere. To this end, the present paper deals with the physicochemical properties of Mediterranean aerosols. In addition, the results are analyzed using simulations of a 2D numerical model to investigate the dispersion of the submicronic particles, typical of anthropogenic contribution in coastal areas.

\section{Field site and experiments}

The experiments took place from $5^{\text {th }}$ May to $29^{\text {th }}$ May 2007. The present paper deals more particularly with the aerosol data recorded from $23^{\text {rd }}$ to $28^{\text {th }}$ May. The study area is the Toulon-Hyères bay (Fig. 1) located on the French Riviera, between 6.15 and 6.25 degrees east longitude and at 43 degrees north latitude. 
Measurements of aerosol particle size distributions and meteorological parameters were performed at the extreme west point of the island of Porquerolles (Fig. 1). The measurement station is located in a natural reserve with no potential local anthropogenic sources around. Fig. 1 shows that the sea state depends on the wind's trajectory over water, i.e., the fetch. The station is exposed to air masses from the open sea, which corresponds to infinite fetches as defined by the criterion applied for fully developed sea conditions (Hsu [10]), as well as to air masses originating over the European mainland, with very short fetch $(5 \mathrm{~km})$, that represent continentally polluted conditions. In Fig. 2, the wind vectors recorded during the sampling periods are reported.

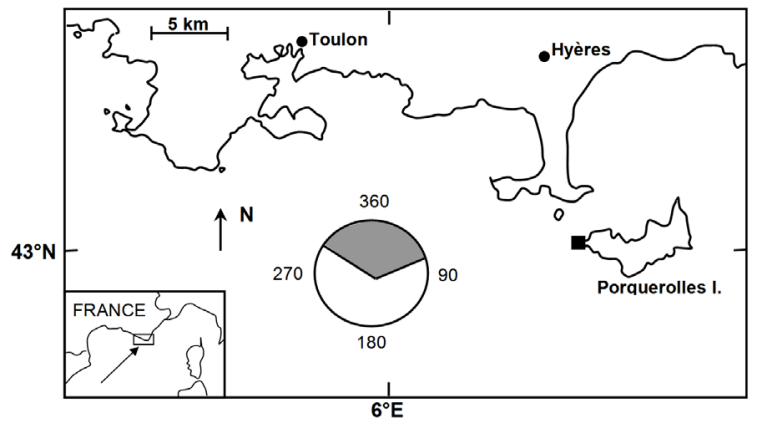

Figure 1: Detailed view of the study area. The black square shows the location of the experimental station.

\subsection{Sampling and analytical procedures}

Meteorological data measured at the site were wind speed, wind direction, air and sea temperature and relative humidity. For chemical characterization, aerosols were sampled directly in the atmosphere with two low pressure cascade impactors (Dekati) from $5^{\text {th }}$ May to $10^{\text {th }}$ May 2007. The first one was a $30 \mathrm{lpm}$ 13-stages low pressure cascade impactor which cut-off aerodynamic diameters were $0.03,0.06,0.108,0.17,0.26,0.4,0.65,1,1.6,2.5,4.4,6.8$ and $9.97 \mu \mathrm{m}$ dedicated to the organic carbon (OC) and elemental carbon (EC) analysis. The second impactor operated at $20 \mathrm{lpm}$ with approximately the same size cut diameters for subsequent analysis with Ion Chromatography. Sampling duration varied from 4 to $24 \mathrm{~h}$. The collection plates were custom-made out of aluminium foil for Ionic Chromatography analysis and quartz Whatman for the OC/EC analysis. Blank levels were performed on a sample-to-sample basis. Before and after sampling, the collection plates were weighted, using a microbalance UMT2 Metler Toledo, after $24 \mathrm{~h}$ in the clean room in order to reach the equilibrium temperature and relative humidity. Impaction plates were stored at $-4{ }^{\circ} \mathrm{C}$ before analysis. The soluble inorganic compounds were analyzed by IC. The collection plates were extracted in their storage bottle for few minutes using $10 \mathrm{~mL}$ of Milli-Q water. Cations $\left(\mathrm{Na}+, \mathrm{NH}_{4}^{+}, \mathrm{K}^{+}, \mathrm{Mg}^{2+}\right.$ and $\mathrm{Ca}^{2+}$ ) were analysed with a Dionex ICS-1500 chromatograph, using a CS16 column, a CG16 guard column and chemical regeneration was made with a CSRS ULTRA II autosuppressor 


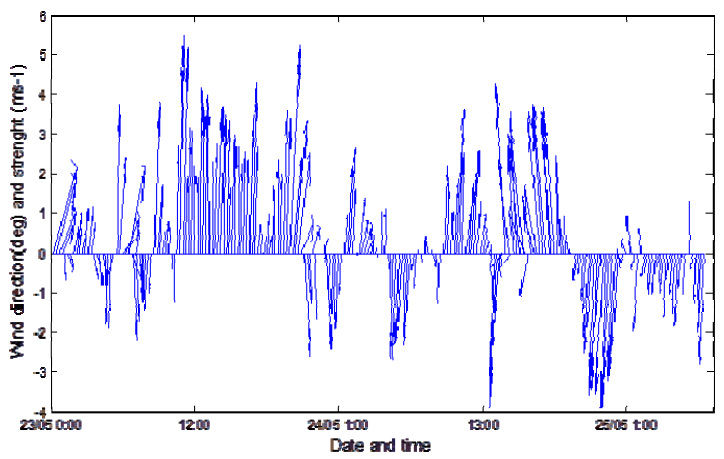

(a)

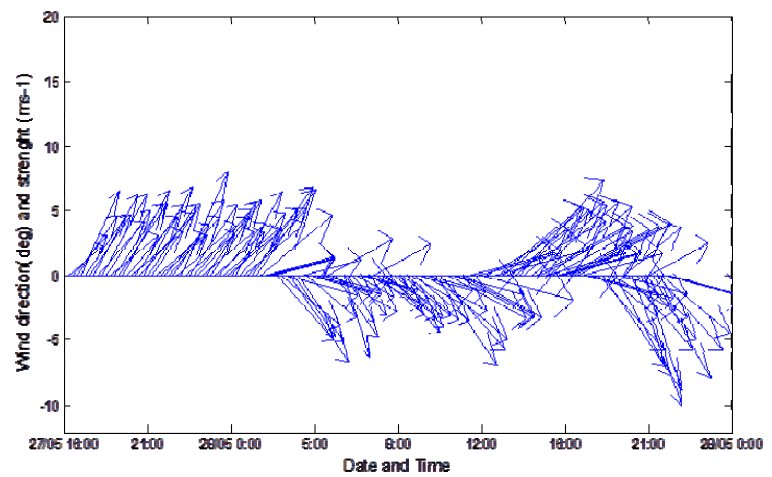

(b)

Figure 2: (a) Wind direction and strength from $23^{\text {rd }}$ to $25^{\text {th }}$ May dealing with low offshore wind period. (b) Wind direction and strength the 28/05/07 dealing with high offshore wind period.

and a $0.20 \%$ MSA eluent. Concentrations of major water-soluble anions $\left(\mathrm{Cl}^{-}\right.$, $\mathrm{NO}_{3}{ }^{-}, \mathrm{SO}_{4}{ }^{2-}$ and $\mathrm{C}_{2} \mathrm{O}_{4}{ }^{2-}$ ) were determined with a Dionex IC25 chromatograph, using an AS11 column, an AG11 guard column and an ASRS ULTRA II autosuppressor. Injection was performed a $\mathrm{KOH}$ gradient and an EG40 eluant generator. Anions and cations are injected in parallel with an AS40 automated sampler with the injection loop of $750 \mu \mathrm{L}$. The collection plate blank arithmetic averages were substracted from sample concentrations. For samples under the detection limit, we used the average blank value to rise up their detection levels. The carbonaceous fraction (OC and EC) was determined by a thermo-optical technique with correction of pyrolysis by laser transmission (the TOT method) on a Sunset Lab analyser (Birch and Cary [11]).

\subsection{Campaign overview}

The present study focuses on both low and high offshore wind periods. For low winds, the air masses can come from the north or northwest directions and are 
characterized by the influence of a strongly urbanized coastal area. The high wind speed periods studied in the present paper correspond to meteorological conditions typical of the study area, and defined as "Mistral" conditions. They are associated to high wind speeds of northwestern origin and correspond to a short $25 \mathrm{~km}$-fetch on the island of Porquerolles (see Fig. 1).

\section{The Mediterranean Aerosol Concentration Model, MACMod}

The Mediterranean Aerosol Concentration Model, MACMod, is a twodimensional unsteady model developed to describe the evolution of aerosol concentrations in the marine area (for more details, see Tedeschi and Piazzola [12]). The budget equation is integrated over a Cartesian grid (regular in the horizontal direction and stretched in the vertical direction), using the finite volume method (Patankar and Spalding [13]). The environmental data such as the wind velocity, the friction velocity and the air and sea temperatures, can be either pre-computed with a meteorological model for a real case modeling, taken from a theoretical parameterization (this will be the case for the present study) or set to a constant value. The environmental data can be updated regularly with time (which is especially relevant when using a mesoscale meteorological model to drive MACMod). Subroutines were developed for each physical process, such as the aerosol source function, aerosol deposition on the marine surface, gravitational settling or turbulent dispersion. The user can select from various expressions to model the underlying physics. According to use, an empirical vertical profile of aerosol concentration can be applied in input of the model following the work of Piazzola and Despiau [14, 15]. In the present study, the initial aerosol concentration was taken to be zero. Initially, in MACMod, the Monahan et al. [16] formulation was used to model the aerosol flux at the sea surface in Open Ocean. Recently, this formulation was improved using aerosol size distributions recorded during the MIRAMER campaign (Demoisson et al. [17]).

\section{Chemical analysis}

The experimental measurements made in May 2007 on the island of Porquerolles allowed for a survey of different anthropogenic and natural compounds of atmospheric aerosols for local meteorological conditions of the Mediterranean coastal area. Among 11 impactor samples, only those acquired during clear and stable meteorological conditions were selected. Total concentrations recorded for major species are reported in Table 1.

For low offshore winds, anthropogenic tracers such as $\mathrm{NH}_{4}^{+}, \mathrm{nss}_{-} \mathrm{SO}_{4}{ }^{2-}$ and $\mathrm{NO}_{3}^{-}$showed concentrations in the range of those already measured in the northern Mediterranean during the FETCH experiment (Sellegri et al. [18]). However, it seems that sulphate concentrations measured at Porquerolles are rather low compared to those acquired during eastern Mediterranean measurements in the Aegean Sea by Eleftheriadis et al. [19] and in the coastal 
Table 1: $\quad$ Concentrations of major species $\left(\mu \mathrm{g} \mathrm{m}^{-3}\right)$.

\begin{tabular}{lccccccccccc}
\hline & $\mathrm{Cl}$ & $\mathrm{NO}_{3}$ & $\mathrm{SO}_{4}$ & Oxalate & $\mathrm{Na}$ & $\mathrm{NH}_{4}$ & $\mathrm{~K}$ & $\mathrm{Mg}$ & $\mathrm{Ca}$ & $\mathrm{OC}$ & $\mathrm{EC}$ \\
\hline $\begin{array}{l}\text { Low } \\
\text { wind }\end{array}$ & 0.84 & 1.52 & 3.1 & 0.17 & $\mathbf{0 . 7 9}$ & 0.48 & 0.13 & 0.13 & 0.3 & 4.97 & 0.33 \\
\hline Mistral & 5.14 & 0.24 & 1.18 & 0.02 & $\mathbf{2 . 9 9}$ & 0.08 & 0.12 & 0.41 & 0.1 & 5.37 & 0.13 \\
\end{tabular}

site of Finokalia by Bardouki et al. [20], i.e., $10.12 \pm 1.10 \mu \mathrm{g} \mathrm{m}^{-3}$ and $6.88 \pm$ $0.96 \mu \mathrm{g} \mathrm{m}^{-3}$, respectively. We also found the most important contribution of nitrate to be in the super micron range. This could be due to the fact that the fixation of nitrogen species is favoured by the presence of sea-sprays. Indeed, in the literature, nitrate has often been found in the super micron range when seasalt is present (e.g., Sellegri et al. [18]) and hence suspected to originate from the reaction of $\mathrm{NaCl}$ with $\mathrm{HNO}_{3}$ on the particles surface. However, the present results show that these reaction are probably favourized by the occurrence of lull periods characterizing by sea-spray deposition. Indeed, for high wind speed periods of offshore wind, the nitrate are substantially reduced (Fig. 3). For high northwest winds, sodium and chloride concentrations show the highest concentrations despite the fact that it corresponds to short fetch conditions, i.e., $25 \mathrm{~km}$. Hence, we can conclude that a $25 \mathrm{~km}$ fetch is enough to efficiently load the air mass with sea-sprays up to an equilibrium determined by wind speed. The $\mathrm{Na}+$ and $\mathrm{Cl}^{-}$concentrations are comparable to those found by Sellegri et al. [18] during the FETCH experiment under high wind speed conditions of southern sectors in aerosols sampled on board of a ship sailing off the Mediterranean coast for larger fetch of about $80 \mathrm{~km}$. Under Mistral conditions, we observe the smallest concentration of anthropogenic tracers, which could be due to a strong dispersion of the pollutants typical of large wind speed episodes (Piazzola and Despiau [21]). However, organics contribute by 39\% 34\% to the particle mass for coastal low wind speed and mistral conditions, respectively. The major contribution of the carbonaceous compounds is found in the sub micron mode (Fig. 3).

In addition, in contrast with the other anthropogenic tracers, the OC and EC contribution does not seem to be reduced by the turbulent dispersion due to high wind speeds of the Mistral episode (see Table 1). Although in our case, OC is likely rather composed of anthropogenic species, the relatively large concentrations of organic compounds can be partly due to enhanced by biological activities as it can occur during blooming periods. Indeed, Mediterranean area can cause an excess in nutrients, as phosphate and nitrate compounds resulting in eutrophication processes throughout the year (Jamet et al. [22]). The size distribution of marine aerosol particles has also been proved to experience significant seasonal variations (Yoon et al. [2]), which could also be due to the biological activity. This could explain why the OC contribution 


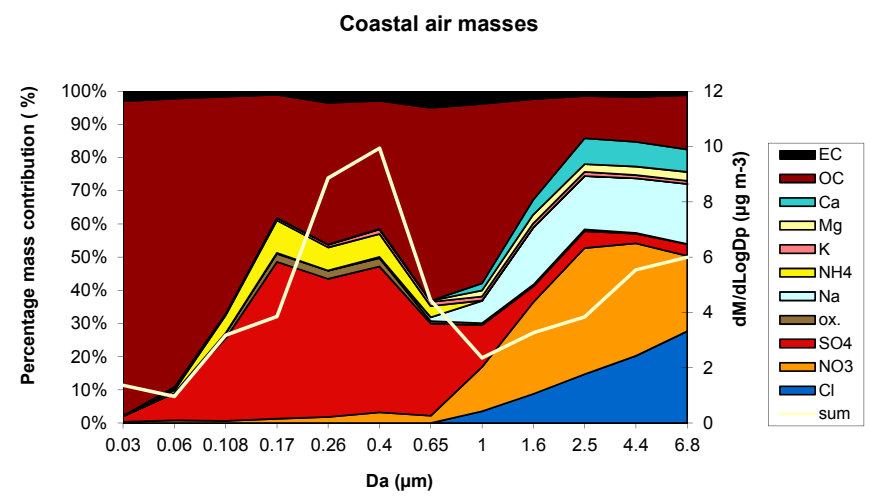

(a)

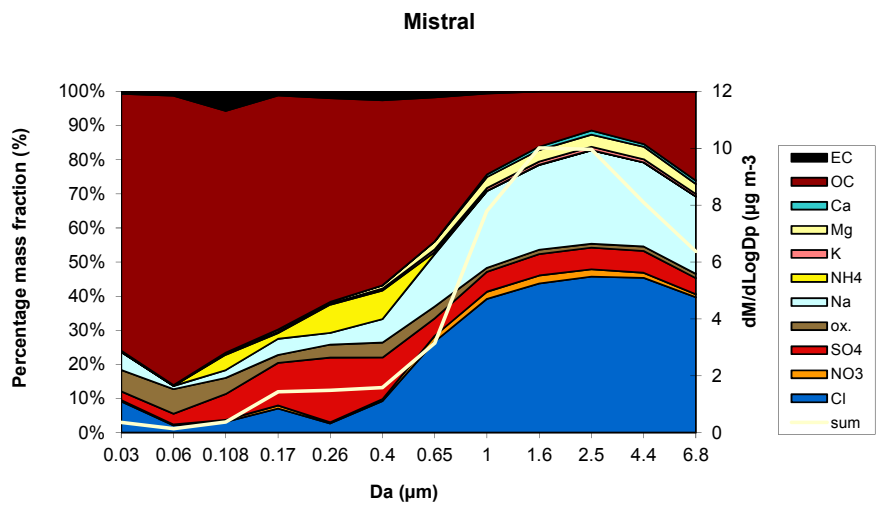

(b)

Figure 3: (a) Size-segregated percentage contribution of chemical species $\left(\mathrm{ugm}^{-3}\right)$ in aerosol sampled during low offshore wind periods. (b) Size-segregated percentage contribution of chemical species $\left(\mathrm{ugm}^{-3}\right)$ in aerosol sampled during high offshore wind periods.

reported in the present results was significantly higher and closer to the ones observed in the sub micron mode during the phytoplanctonic blooming period in the Northern Atlantic coastal area (Cavalli et al. [23]).

\section{Model calculations}

To investigate the offshore conditions, simulations were made using the MACMod model to investigate both low and high wind speed periods. Fig. 4 shows the evolution of the ratio between the aerosol concentration of the $0.5 \mu \mathrm{m}$ particles at the coastline and the one measured at $25 \mathrm{~km}$ fetch versus the distance to the coastline for both low and high offshore wind conditions. The $0.5 \mu \mathrm{m}$ particles are considered characteristics of the continental and/or anthropogenic 
influence. We can note that the $0.5 \mu \mathrm{m}$ particles are reduced for high wind speed of $15 \mathrm{~ms}^{-1}$. However, Fig. 4 shows that the reduction of the concentrations does not exceed $30 \%$ along $25 \mathrm{~km}$. This show that the lifetime of the submicronic particles in the atmosphere, which are characteristics of the anthropogenic influence in coastal areas is quite large.

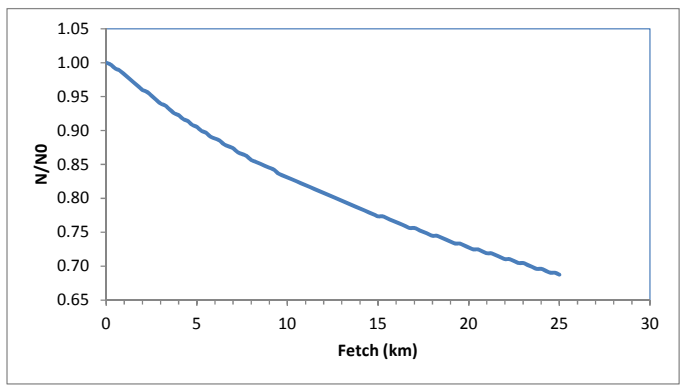

Figure 4: Evolution of the ratio between the aerosol concentrations of the $0.5 \mu \mathrm{m}$ particles at the coastline and the one measured at $25 \mathrm{~km}$ fetch versus the distance to the coastline for high offshore wind of $15 \mathrm{~ms}^{-1}$.

\section{Discussion}

The aim of this work was to provide a physicochemical analysis of aerosols measured for meteorological conditions characteristics of coastal areas. The generability of the results has to be discussed since the measuring campaign was very short. In accordance with Piazzola and Despiau [14], we noted a substantial contribution of sea-sprays in the aerosol concentrations measured during high wind speed periods of northwest direction, although this episode corresponds to short fetch conditions, i.e. 25 kilometers. In addition, high wind speed periods of northwest wind are characterized by an absence of most of continental polluted absorbing aerosols, whereas a rather constant contribution of anthropogenic particles was observed for low wind speed periods. This shows that at high wind speeds, the sea surface production is the dominant mechanism while low wind speed periods allow accumulation of high continental aerosol concentrations due to a slower atmospheric dispersion. However, Table 1 shows that the OC and EC concentrations are rather stables when comparing the low wind speed periods and high winds of northwest direction and close to those observed in the submicron mode during the phytoplanctonic blooming period in the Northern Atlantic coastal area (Cavalli et al. [23]). Although it is suspected that a large fraction of organic compounds found in the aerosol phase comes from anthropogenic sources, the relatively large concentrations of organic compounds can also be partly due to larger amounts of organics in the sea water. These organics can be produced either biologically or be already present in the sea water as primary pollutants. On one side, biological activity is primarily induced by light and furthermore depends strongly on the input of nutrients into the sea. 
High concentrations of pollutants have been observed in the Mediterranean area, in particular from the run-off after a rain which may cause an excess of phosphate and nitrate compounds resulting in eutrophication. Biological studies conducted in the Toulon bay and in the Hyeres bay, have indeed revealed an excess in nutrients and eutrophication processes throughout the year (Jamet et al. [22]). A large fraction of the sub-micron mode was composed of organics, for aerosols sampled during purely marine air mass episodes, closely followed by sulphate. Both compounds are presumably of anthropogenic origin, but this hypothesis should be checked in future work.

The variation of the height of the boundary layer could be responsible for the aerosol concentration variations due to dilution effects. Actually, the mixed layer shows little variations during the whole period of the low wind speed episode (from approximately $80 \mathrm{~m}$ height to a maximum value during the daytime at $260 \mathrm{~m}$ height). This has probably a minor influence on the aerosol concentration variations during Episode 1. However, the mixed layer depth is higher for high wind speed of offshore direction in accordance with the fact that the mixed layer grows rapidly under turbulent conditions.

For low wind speeds, we found the most important contribution of nitrate to be in the super micron range. Previous work conducted by Sellegri et al. [18] then showed the concomitant presence of sea-sprays and high levels of anthropogenic species such as nitrate. These reaction are probably favourized by the occurrence of lull periods characterizing by sea-spray deposition since for high wind speed periods of offshore wind, the nitrate are substantially reduced (Fig. 3).

The simulations of the aerosol transport using the 2D MACMod Model show that the reduction of concentrations of submicron aerosols is about $30 \%$ along a $25 \mathrm{~km}$ fetch and for high wind speed of $15 \mathrm{~ms}^{-1}$. This means that the lifetime of the submicron aerosols in the atmosphere, which are characteristics of the anthropogenic influence in coastal areas, is quite large.

\section{Conclusion}

The chemical analysis, combined with the high aerosol concentrations measured on the island of Porquerolles, make think that air masses are strongly impacted by pollution which is present over the Mediterranean basin. However, in spite of the large number of anthropogenic aerosol sources of such urbanized coastal sites as the Mediterranean study area, the anthropogenic compounds seem to be dispersed within the lower atmosphere resulting in the dominant signature of seasalts for Mistral conditions. However, the model simulations show that the lifetime of the submicronic particles in the atmosphere, which are characteristics of the anthropogenic influence in coastal areas is rather large.

\section{References}

[1] Andreae, M.O. Climate effects of changing atmospheric aerosol levels, in World survey of climatology. Future climate of the world, edited by A. Henderson-Sellers, Vol. 16, pp. 341-392, 1995. 
[2] Yoon, Y. J., Ceburnis, D., Cavalli, F., Jourdan, O., Putaud, J.P., Facchini, M.C., Decesari, S., Fuzzi, S., Sellegri, K., Jennings, S.G. and O’Dowd, C.D. Seasonal characteristics of the physicochemical properties of North Atlantic marine atmospheric aerosols. Journal of Geophysical Research, 112, 2007.

[3] Piazzola, J., Forget, P., Lafon, C. and Despiau, S. Spatial Variation of SeaSpray Fluxes over a Mediterranean Coastal Zone Using a Sea-State Model. Boundary-Layer Meteorology, 132 (1), 167-183, 2009.

[4] Mulcahy, J.P., O’Dowd, C.D., Jennings, S.G. and Ceburnis, D. Significant enhancement of aerosol optical depth in marine air under high wind conditions. Geoph. Research Letters, 35, L16810, doi: 1029 /2008GL034303, 2008.

[5] Knipping, E. M. and Dabdub, D. Impact of chlorine emissions from sea-salt aerosol on coastal urban ozone. Environmental Science Technology, 37(2), 275-284, 2003.

[6] Paerl, H.W., Boynton, W.R..., Dennis, R.L., Driscoll, C.T., Greening, H.S., Kremer, J.N., Rabalais, N.N. and Seitzinger, S.P. Atmospheric deposition of nitrogen in coastal waters: biogeochemical and ecological implications, In: Valigura, R.A., Alexander, R.B., Castro, M.S., Meyers, T.P., Paerl, H.W., Stacey, P.E. and Turner, R.E. (Eds.), Nitrogen loading in coastal water bodies: an atmospheric perspective. American Geophysical Union, Washington DC (USA), pp. 11-52, 2001.

[7] Ceburnis, D., O’Dowd, C.D., Jennings, G.S., Facchini, M.C., Emblico, L., Decesari, S., Fuzzi, S. and Sakalys, J. Marine aerosol chemistry gradients: Elucidating primary and secondary processes and fluxes. Geoph. Research Letters, 35, L07804, doi:10.1029/2008GL033462, 2008.

[8] Jamet, J.L., Bogé, G., Richard, S., Geneys, C. and Jamet, D. The zooplankton community in bays of Toulon area (northwest Mediterranean sea, France). Hydrobiologia, 457, 155-165, 2001.

[9] K. Sellegri, Y. J. Yoon, S. G. Jennings, C. D. O’Dowd, L. Pirjola, S. Cautenet, Hongwei Chen, Thorsten Hoffmann. Quantification of Coastal New UltraFine Particles Formation from in situ and Chamber Measurements during the BIOFLUX Campaign. Environmental Chemistry, vol. 2, no. 4, 2005.

[10] Hsu, S.A. A mechanism for the increase of wind stress (drag) coefficient with wind speed over water surfaces : A parametric model. Journal Physical Oceanography, 16, 144-150, 1986.

[11] Birch, M. E. and Cary, R. A. Elemental carbon based method for monitoring occupational exposure to particulate diesel exhaust. Aerosol Science Technology, 25, 221-241, 1996.

[12] Tedeschi G. and Piazzola, J. Development of a 2D marine aerosol transport model, application to the influence of thermal stability in the marine atmospheric boundary layer', Atm. Research., Vol. 101, pp. 469-479, 2011.

[13] Patankar, S V. and Spalding, D. B. "A calculation procedure for heat, mass and momentum transfer in three-dimensional parabolic flows." Journal of 
Heat Mass Transfer 15: 1787-1806.Piazzola, J. and Despiau, S., (1997a). Contribution of marine aerosols in the particle size distributions observed in Mediterranean coastal zone. Atmospheric Environment, 31 (18), 2991-3009, 1972.

[14] Piazzola, J. and Despiau, S. Contribution of marine aerosols in the particle size distributions observed in Mediterranean coastal zone. Atmospheric Environment, 31 (18), 2991-3009, 1997a

[15] Piazzola, J. and Despiau, S. The vertical variations of extinction and atmospheric transmission due to aerosol particles close above the sea surface in Mediterranean coastal zone. Optical Engineering, 37, doi:10.1117/1.601695, 1998.

[16] Monahan, E C, Davidson, K. L. and D. E. Spiel. "A model of marine aerosol generation via whitecaps and wave disruption." In Oceanic whitecap and their role in air-sea exchange processes, edited by E. C. Monahan and G. Mac Niocaill, 167-174. Reidel, Dordrecht, 1986.

[17] Demoisson, A, Tedeschi, G and J. Piazzola. A model for the atmospheric transport of sea-salt particles in coastal areas, Atoms. Research, 2013 (submitted).

[18] Sellegri, K., Gourdeau, J., Putaud, Jean J.-P., Despiau, S. Chemical Composition of Marine Aerosol in a Mediterranean Coastal Zone during the FETCH Experiment. Journal of Geophysical Research vol. 106 p. 12023-12037, $\mathrm{N}^{\circ} \mathrm{JRC} 23186,2001$.

[19] Eleftheriadis, K., I. Colbeck, I., C. Housiadaa, C., M. Lazaridis, M., N. Mihalopoulos, N., C. Mitsakou, C., J. Smolık, J. and V. Zdımal, V. Size distribution, composition and origin of the submicron aerosol in the marine boundary layer during the eastern Mediterranean "SUB-AERO", experiment. Atmospheric Environment, 40 6245-6260, 2006.

[20] Bardouki H, Liakakou H, Economou C, Scaire J, Smolik J, Zdimal V, Eleftheriadis K, Lazaridis M, Dye C, Mihalopoulos N. Chemical composition of size resolved atmospheric aerosols in the eastern Mediterranean during summer and winter. Atmospheric Environment 37, 195-208, 2003.

[21] Piazzola, J. and Despiau, S. Vertical distribution of aerosol particles near the air-sea interface in coastal zone. J. of Aerosol Sci., 28 (8), 1579-1599, $1997 b$.

[22] Jamet, J.L., Bogé, G., Richard, S., Geneys, C. and Jamet, D. (2001). The zooplankton community in bays of Toulon area (northwest Mediterranean sea, France). Hydrobiologia, 457, 155-165.

[23] Cavalli, F., Facchini, M.C., Decesari, S., Mircea, M., Emblico, L., Fuzzi, S., Ceburnis, D., Yoon, Y.J., O’Dowd, C.D., Putaud, J.-P. and Dell'Acqua, A. Advances in characterization of size-resolved organic matter in marine aerosol over the North Atlantic. Journal Geophysical Research, 109, D24215, doi:10.1029/2004JD005137, 2004. 